\title{
Over-supplementation of vitamin $D$ in two patients with primary hyperparathyroidism
}

\author{
Claudia Battista, ${ }^{1}$ Raffaella Viti, ${ }^{1}$ Salvatore Minisola, ${ }^{2}$ Iacopo Chiodini, ${ }^{3}$ \\ Vincenzo Frusciante, ${ }^{4}$ Alfredo Scillitani, ${ }^{1}$ Vincenzo Carnevale ${ }^{5}$
}

\begin{abstract}
${ }^{1}$ Unit of Endocrinology, “Casa Sollievo della Sofferenza" Hospital, IRCCS, San Giovanni Rotondo (FG), ${ }^{2}$ Department of Clinical Sciences, University of Roma "Sapienza", ${ }^{3}$ Unit of Endocrinology, Department of Medical Sciences, Fondazione Policlinico IRCCS, University of Milan, ${ }^{4}$ Unit of Nuclear Medicine, ${ }^{5}$ Unit of Internal Medicine, "Casa Sollievo della Sofferenza" Hospital, IRCCS, San Giovanni Rotondo (FG), Italy
\end{abstract}

\begin{abstract}
OBJECTIVE: To describe the biochemical effects of an over-supplementation of vitamin D3 in two patients with primary hyperparathyroidism (PHPT). DESIGN: Two patients (A and B) with PHPT took erroneously $2,400,000 \mathrm{U}(300,000 \mathrm{U} /$ day for 8 days) and 4,500,000U (300,000 $\mathrm{U} /$ day for 15 days) of cholecalciferol, respectively. They were followed for 4 months and ionized calcium, creatinine, PTH, 25 hydroxy-vitamin $\mathrm{D}, 1,25(\mathrm{OH})_{2} \mathrm{D}$ and urinary calcium/creatinine levels were measured. Finally, the patients were operated on and a parathyroid adenoma was removed in both. RESULTS: One week after the last dose of vitamin $D$, serum ionized calcium (iCa) rose from 1.35 to $1.41 \mathrm{mMol} / \mathrm{L}$ (n.r. 1.14-1.31) for patient $A$, and from 1.43 to 1.62 for patient $\mathrm{B}$, while fasting urinary Calcium/Creatinine $(\mathrm{uCa} / \mathrm{Cr})$ augmented from 0.31 to $0.50 \mathrm{mg} /$ $\mathrm{mg}$, and from 0.32 to 0.55 , respectively. During the follow-up, the average levels of iCa were $1.37 \pm 0.03$ and $1.48 \pm 0.07 \mathrm{mMol} / \mathrm{L}$, while those of $\mathrm{uCa} / \mathrm{Cr}$ were $0.29 \pm 0.13$ and $0.32 \pm 0.13$, both iCa and $\mathrm{uCa} / \mathrm{Cr}$ levels returning to baseline values within 4 months. CONCLUSIONS: The unintentional over-supplementation of vitamin D in the two PHPT patients caused a moderate and temporary increase of hypercalcemia and hypercalciuria and was not associated with clinical signs of toxicity.
\end{abstract}

Key words: Hypercalcemia, Hypercalciuria, Primary hyperparathyroidism, Safety, Toxicity, Vitamin D

\section{INTRODUCTION}

Hypovitaminosis D is common in patients with

Address for correspondence:

Alfredo Scillitani, Unit of Endocrinology, Ospedale "Casa

Sollievo della Sofferenza”, IRCCS 71013, San Giovanni

Rotondo (FG), Italy, Tel.: +390882410625,

Fax: +390882410627, E-mail: alscill@tin.it

Received 29-09-2012, Accepted 05-03-2013 primary hyperparathyroidism (PHPT) ${ }^{1,2}$ Some studies suggest that vitamin $\mathrm{D}$ deficiency may promote a marked parathyroid cell proliferation in PHPT patients, ${ }^{3}$ whilst the maintenance or restoration of vitamin D sufficiency is capable of preventing or reversing this phenomenon..$^{1-5}$ The aforementioned considerations have been acknowledged by the recent Guidelines for the Management of Asymptomatic 
Primary Hyperparathyroidism, that recommend the correction of vitamin D deficiency in these patients. ${ }^{6}$ Nevertheless, vitamin D supplementation is not prescribed to patients with primary hyperparathyroidism (PHPT) because of the concerns regarding possible exacerbation of hypercalcemia and/or hypercalciuria. ${ }^{1,7-10}$ Moreover, the recent review on calcium and vitamin D by the Institute of Medicine raised concerns about the safety of vitamin D supplements. ${ }^{11}$ Consequently, data on vitamin D supplementation in PHPT are limited. We report here two patients with PHPT and vitamin D deficiency who erroneously took an over-supplementation of vitamin D3. They were followed for 4 months by evaluating the main biochemical parameters of calcium homeostasis.

\section{CASE REPORT}

Two women (patient A aged 53 years, BMI 28, and patient B aged 63 years, BMI 24), referred to our Endocrinology Department for hypercalcemia (patient A: total calcium $10.80 \mathrm{mg} / \mathrm{dL}$, patient B: 11.44), had a diagnosis of PHPT and vitamin D deficiency. Accord- ing to our experience, in healthy subjects ${ }^{12}$ a single oral dose of cholecalciferol 300,000 IU should have been prescribed, but erroneously, the two patients were given 2,400,000 IU (300,000 IU/day for 8 days, patient A) and 4,500,000 IU (300,000 IU/day for 15 days, patient B). The patients were followed for 4 months in our outpatient clinics and gave witnessed informed consent to data collection and examination.

One week after the last dose of vitamin $\mathrm{D}$, serum ionized calcium (iCa) rose from 1.35 to $1.41 \mathrm{mMol} / \mathrm{L}$ (n.r. 1.14-1.31) for patient A, and from 1.43 to 1.62 for patient $\mathrm{B}$, while fasting urinary Calcium/Creatinine ( $\mathrm{uCa} / \mathrm{Cr}$ ) augmented from 0.31 to $0.50 \mathrm{mg} / \mathrm{mg}$, and from 0.32 to 0.55 , respectively (Figure 1). During the follow-up, the average levels (Mean \pm SD) of iCa were $1.37 \pm 0.03$ and $1.48 \pm 0.07 \mathrm{mMol} / \mathrm{L}$, while those of $\mathrm{uCa} / \mathrm{Cr}$ were $0.29 \pm 0.13$ and $0.32 \pm 0.13$. Both $\mathrm{iCa}$ and $\mathrm{uCa} / \mathrm{Cr}$ levels returned to baseline values within 4 months.

25-hydroxy-cholecalciferol (25OHD) levels rose quickly and attained values higher than $150 \mathrm{ng} / \mathrm{mL}$ during the first month in patient $\mathrm{B}$ and during the

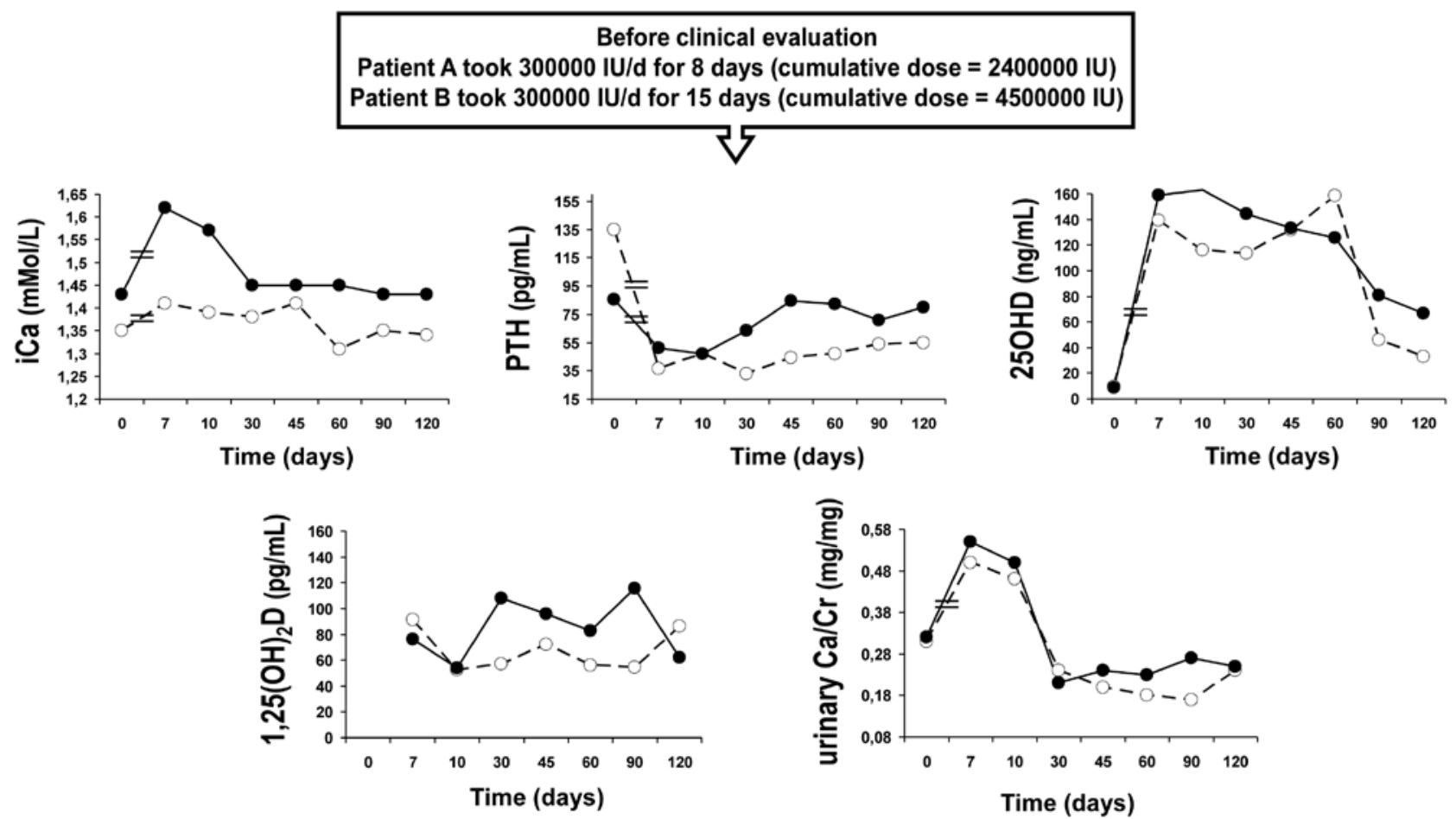

FIGURE 1. Biochemical data of the vitamin D3 over-treatment Variations of the levels of iCa, PTH, 25OHD, 1,25(OH) 2 D and urinary $\mathrm{Ca} / \mathrm{Cr}$ during the 4 months after vitamin $\mathrm{D}$ loading dose in patient $\mathrm{A}(\mathrm{O})$ and $\mathrm{B}(\bullet)$. 
second month in patient $\mathrm{A}$, reaching $\leq 70 \mathrm{ng} / \mathrm{mL}$ by the end of the observation period (Figure 1). PTH levels, in turn, quickly declined after the vitamin D load and began to rise again from the second month. The changes of PTH and 25(OH)D levels were significantly and negatively correlated (patient A: $\mathrm{r}=-0.71$, $p=0.03$; patient $B: r=-0.71, p=0.05$ ), while no significant correlation was found between $1,25(\mathrm{OH})_{2} \mathrm{D}$ variations and changes of PTH or 25OHD levels.

The patients were encouraged to markedly increase their daily water intake (more than 3 litres/ day). They did not develop any symptom or clinical sign of hypercalcemia. Serum creatinine levels did not change over time (Mean $\pm \mathrm{SD}, 0.83 \pm 0.04 \mathrm{mg}$ / $\mathrm{dL}$ for patient $\mathrm{A} ; 0.49 \pm 0.04$ for patient $\mathrm{B}$ ) and neither patient developed urolithiasis. After 4 months of vitamin D loading the patients were operated on, because of osteoporosis, and a parathyroid adenoma was removed in both. One year after surgery the patients had not developed any complication and serum, urinary and hormonal data were in the normal range.

\section{DISCUSSION}

Despite medical experts' recommendation to maintain serum 25-hydroxyvitamin D levels above 20 $\mathrm{ng} / \mathrm{mL}$ in PHPT patients, ${ }^{6}$ vitamin D supplementation is often avoided in these patients because of fear of exacerbating hypercalcemia and/or hypercalciuria., 1,-10 Moreover, the recent review on calcium and vitamin $\mathrm{D}$ by the Institute of Medicine raised concerns about the safety of vitamin D supplementation. ${ }^{11}$

In normal subjects the threshold for vitamin D toxicity has not been established to date, though $25(\mathrm{OH}) \mathrm{D}$ concentration above $150 \mathrm{ng} / \mathrm{ml}$ is sometimes associated with hypercalcemia. ${ }^{13}$ Several factors have been implicated in individual susceptibility to vitamin D toxicity, among them Vitamin D Binding Protein levels (DBP) and their polymorphic variants, ${ }^{14}$ as well as the amount of adipose tissue and, consequently, of fat body mass, which is the storage site of vitamin D in humans. ${ }^{15}$ Data on vitamin D supplementation and toxicity as regards PHPT are limited, so that our patients represent an unintentional and interesting clinical model of vitamin D excess in PHPT. Their $25 \mathrm{OHD}$ levels above $150 \mathrm{ng} / \mathrm{mL}$ induced only a moderate increase of hypercalcemia and hypercalciuria without symptoms of hypercalcemia and/or worsening of the renal function. However, since the most severe effects of excessive doses of vitamin D are manifest during the period of administration and we observed our patients one week after the last dose of vitamin $\mathrm{D}$, we cannot exclude the probability that both serum and urinary calcium levels were higher during vitamin D administration. ${ }^{15}$

The negative correlation we found between 25OHD and PTH levels strongly suggests a vitamin D-dependent mechanism in our patients, a finding which likely could be extrapolated to normal subjects, while it also supports the hypothesis that the local $1 \alpha$-hydroxylase activity of the parathyroid cells could regulate PTH synthesis and secretion. ${ }^{16,17}$

This case report confirms that PTH secretion may be modulated by vitamin $\mathrm{D}$ even in patients with PHPT. The unintentional over-supplementation of vitamin D caused a moderate increase of hypercalcemia and hypercalciuria and was not associated with clinical signs of toxicity. Thus, our cases suggest that there is no concern involved in supplementation for vitamin D deficient PHPT patients.

\section{REFERENCES}

1. Silverberg SJ, Shane E, Dempster DW, Bilezikian JP, 1999 The effects of vitamin D insufficiency in patients with primary hyperparathyroidism. Am J Med 107: 561-567.

2. Carnevale V, Manfredi G, Romagnoli E, et al, 2004 Vitamin D status in female patients with primary hyperparathyroidism: does it play a role in skeletal damage? Clin Endocrinol 60: 81-86.

3. Rao DS, Honasoge M, Divine GW, et al, 2000 Effect of vitamin D nutrition on parathyroid adenomaweight: pathogenetic and clinical implications. J Clin Endocrinol Metab 85: 1054-1058.

4. Rao DS, Agarwal G, Talpos GB, et al, 2002 Role of vitamin $\mathrm{D}$ and calcium nutrition in disease expression and parathyroid tumor growth in primary hyperparathyroidism: a global perspective. J Bone Miner Res 17: N75-N80.

5. Nordenstrom E, Westerdahl J, Lindergard B, Lindblom P, Bergenfelz A, 2002 Multifactorial risk profile for bone fractures in primary hyperparathyroidism. World J Surg 26: 1463-1467.

6. Eastell R, Arnold A, Brandi ML, et al, 2009 Diagnosis of asymptomatic primary hyperparathyroidism: proceedings of the third international workshop. J Clin Endocrinol 
Metab 94: 340-350.

7. Woodhouse NJ, Tun Chot S, Bordier P, Sigurdsson G, Joplin GF, 1973 Vitamin D administration in primary hyperparathyroidism. Clinical Science 44: 3P.

8. Kantorovich V, Gacad MA, Seeger LL, Adams JS, 2000 Bone mineral density increases with vitamin D repletion in patients with coexistent vitamin D insufficiency and primary hyperparathyroidism. J Clin Endocr Metab 85: 3541-3543.

9. Bilezikian JP, 2000 Primary hyperparathyroidism. When to observe and when to operate. Endocrinol Metab Clin North America 29: 465-478.

10. Rankin W, 2011 Primary hyperparathyroidism - is vitamin D supplementation safe? Aust Fam Physician 40: 881-884.

11. Institute of Medicine 2011 Dietary reference intakes for calcium and vitamin D. Washington, DC: The National Academies Press

12. Romagnoli E, Mascia ML, Cipriani C, et al, 2008 Short and Long-Term Variations in Serum Calciotropic Hor- mones after a Single Very Large Dose of Ergocalciferol (Vitamin D2) or Cholecalciferol (Vitamin D3) in the Elderly. J Clin Endocrinol Metab 93: 3015-3020.

13. Jones G, 2008 Pharmacokinetics of vitamin D toxicity. Am J Clin Nutr 88: 582S-586S.

14. Wang TJ, Zhang F, Richards JB, et al, 2010 Common genetic determinants of vitamin $\mathrm{D}$ insufficiency: a genome-wide association study. Lancet 376: 180-188.

15. Vieth R, 2007 Vitamin D toxicity, policy, and science. J Bone Miner Res 22-S2: V64-V68.

16. Segersten U, Correa P, Hewison M, et al, 2002 25-Hydroxyvitamin D3-1 $\alpha$-Hydroxylase Expression in Normal and Pathological Parathyroid Glands. J Clin Endocrinol Metab 87: 2967-2972.

17. Correa P, Segersten U, Hellman P, Akerstrom G, Westin G, 2002 Increased 25-hydroxyvitamin D3 1alpha-hydroxylase and reduced 25-hydroxyvitamin D3 24-hydroxylase expression in parathyroid tumors - new prospects for treatment of hyperparathyroidism with vitamin D. J Clin Endocrinol Metab 87: 5826-5829. 